\title{
Prevalence of Child Physical Abuse among School Children in Mosul City\North of Iraq
}

\author{
Shatha Abdul-Rahman H. Al-Ghurairi' ${ }^{1}$, Eman Al- Khafaf ${ }^{2}$, Hana A. Al seed ${ }^{3}$

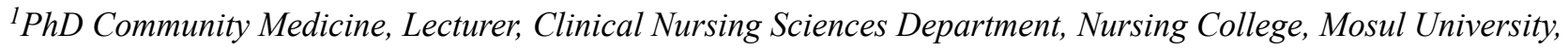 \\ Iraq, ${ }^{2}$ Msc Nursing Psychiatry, Lecturer, Clinical Nursing Sciences Department, Nursing College, Mosul \\ University, Iraq, ${ }^{3}$ Bsc. Nursing, Clinical Nursing Sciences Department, Nursing College, Mosul University, Iraq
}

\begin{abstract}
Background and Aims: Physical abuse is the most critical problem in Mosul city children and the extent of physical abuse is currently unknown. Aim of this study to determine the prevalence of physical abuse among sample of Mosul schoolchildren, aged 12-18 years.
\end{abstract}

Material and Method: A cross-sectional study was carried out from $1^{\text {st }}$, December 2018 to $4^{\text {th }}$ March 2019. The settings chosen by multicultural sampling with a systematic sampling technique of 800 child (396 male and 404 female) using a self-reported questionnaire.

Result: A total of 800 intermediate school children, age group $14-15$ years represent $43.6 \%$, male to female ratio $1: 1,36.1 \%$ of these had experienced physical abuse and $32.6 \%$ abused by mothers. The relationship between the parent educations and father's job shows high significant rate $0.000,0.004$.

Conclusion: physical abuse Mosul city had high prevalent in comparison with others. Psychological and physical problems of children were the main predictors.

Keywords: Physical abuse of children, violence against children, Mosul City.

\section{Introduction}

Our children are often faced with choices that affect their development and safety. One way we do this is to talk with our children ${ }^{[1,2]}$. Child abuse defined as physical injury, emotional abuse, sexual abuse or nonaccidental injuries or trauma inflicted on a child by another person were an active act of maltreatment of children, which can take place in several settings: at home, at school, in the streets, in the workplace ${ }^{[1]}$. A safe environment that supports and promotes children, dignity and development. More than 3 million reports of child abuse are received each year, including half a million reports of child sexual abuse. As a major youthserving organization ${ }^{[1]}$.Parental intimate and partner violence is strong evidence for an overlap between child physical abuse and intimatepartner. Child physical abuse (CPA) injuries can include bruises, broken bones, burns, and abrasions. CPAhappens in all age groups; however, youth ages 12 to 17 have the highest rate of injury from physical abuse ${ }^{[3,4,5,6]}$. The youngest children are the most sensitive to violence and injuries can become severe and cause lifelong consequences or even be life threatening. Shaken baby syndrome and Munchhausen by proxyare examples of such severe types of CPA against small children ${ }^{[1,3,7,8]}$.Factors associated with the CPA are: The proportions of male/female perpetrators are often equal in survey studies ${ }^{[5,9,10,11,12]}$. Addiction and mental disorders/mental functional disorders could lead to poor impulse control. Parent's own history of abuse as a child now seems to be partly broken in Sweden ${ }^{[13]}$.Parental support for corporal punishment has a powerful predictor of violence against children $[3,4,5,6]$. Financial difficulties, parental educational level, unemployment, low socioeconomic status,traumatic experiences of war,medical health problems and singleparent households are all well-known conditions that have been reported as risk factor ${ }^{[4,5,6,7,8]}$. Younger children are more often subjected to abuse than older children are: Disability/chronic disease, behavioral problems are aggressive outbursts, disobedience, attention deficits and other externalizing problems,poor 
health status, poor mental and/or physical health in adulthood $^{[8,9,10,11,12,13,14] \text {. }}$

The objectives of this survey was to measure and describe the CPA aged 12-18 years old, assess differences in the abused children by gender, age, socioeconomic status, parental education, to distinguish the type of response of the child to the insult.

\section{Methodology}

Prior to the actual collection date, a formal administrative approval was obtained. A descriptive cross sectional design was carried out from $1^{\text {st }}$ December 2018 to $4^{\text {th }}$ March 2019. The data was collected from intermediate school (boys and girls). The setting chosen by multicultural sampling taking the most crowded schools in public low and high socioeconomic discrete overall of the left and right sides of Nineveh province. A systematics amp ling technique (every three child) were chosen from the school setting's consisted of(800) child. This divided into(396) male and (404) female through interviewing with children. Data collection form is constructed after reviewing many articles written on this topic. To ensure the validity of the study questionnaire,method and procedures proposed to carried out before the beginning of collection of sample so 6 experts in different specialists related to the field of the present study were chosen. They were asked to review the questionnaire for clarity and adequacy in order to achieve the present study objective. Most of them had agreed that the questionnaire were clear, relevant and adequacy, certain modification were employed based on the experts recommendations and suggestions. Collection and data analysis is done by the researcher manually. Tabulated and presented in a descriptive form. Percentage and chi square are used in calculation and description of the results by SPSS Program version 25 .

\section{Results}

Table 1: Social and demographic characteristics of study sample

\begin{tabular}{|c|c|c|c|}
\hline Demographic Characteristics & Estimate & Freq. & $\%$ \\
\hline \multirow{3}{*}{ Age } & $12-13$ years & 220 & 27.5 \\
\hline & $14-15$ years & 349 & 43.6 \\
\hline & 15 years and above & 231 & 28.9 \\
\hline \multirow{2}{*}{ Gender } & Male & 396 & 49.5 \\
\hline & Female & 404 & 50.5 \\
\hline \multirow{2}{*}{ Type of Family } & Single Family & 505 & 63.1 \\
\hline & Multiple Family & 295 & 36.9 \\
\hline \multirow{3}{*}{$\begin{array}{l}\text { Number of the children in the } \\
\text { Family }\end{array}$} & $2-3$ & 106 & 13.3 \\
\hline & $4-5$ & 254 & 31.8 \\
\hline & 5 or more & 440 & 55.0 \\
\hline \multirow{2}{*}{ Type of Housing } & Possess & 525 & 65.6 \\
\hline & Rent & 275 & 34.4 \\
\hline \multirow{3}{*}{ House Rooms } & $1-2$ & 169 & 21.1 \\
\hline & $3-4$ & 491 & 61.4 \\
\hline & 5 or more & 140 & 17.5 \\
\hline \multicolumn{2}{|c|}{ Total } & 800 & 100.0 \\
\hline
\end{tabular}

Table 1:shows that age group $14-15$ year represent $43.6 \%$. male to female ratio approximately 1:1. 
Table 2: Abuse characteristic of the study samples

\begin{tabular}{|c|c|c|c|}
\hline The Abuse Children & Estimate & Freq. & $\%$ \\
\hline \multirow{2}{*}{ Child Abuse } & Not Abused & 511 & 63.9 \\
\hline & Abused & 289 & 36.1 \\
\hline \multirow{6}{*}{ Who Hits the Child } & Father & 230 & 28.8 \\
\hline & Mother & 261 & 32.6 \\
\hline & Brothers & 188 & 23.5 \\
\hline & Sisters & 42 & 5.3 \\
\hline & Friends & 55 & 6.9 \\
\hline & In School & 24 & 3.0 \\
\hline \multirow{6}{*}{$\begin{array}{l}\text { Age of the child when started hel } \\
\text { she hits }\end{array}$} & $1-2$ & 150 & 18.8 \\
\hline & $3-5$ & 101 & 12.6 \\
\hline & 6-8 & 147 & 18.4 \\
\hline & $9-12$ & 198 & 24.8 \\
\hline & $13-15$ & 139 & 17.4 \\
\hline & 16 or more & 65 & 8.1 \\
\hline \multirow{3}{*}{ Why the child hits } & Study & 332 & 41.5 \\
\hline & Bad manners & 167 & 20.9 \\
\hline & Others & 301 & 37.6 \\
\hline \multirow{3}{*}{ The child trust } & Parents & 496 & 62.0 \\
\hline & Friends & 123 & 15.4 \\
\hline & None & 181 & 22.6 \\
\hline \multicolumn{2}{|l|}{ Total } & 800 & 100.0 \\
\hline
\end{tabular}

Table $2: 36.1 \%$ is the prevalence of abuse in family sample and $32.6 \%$ of children abused by their mothers.

Table 3: Psychological and medical problem of the study sample

\begin{tabular}{|l|l|c|c|}
\hline The Problems & Estimate & Freq. & \% \\
\hline \multirow{4}{*}{$\begin{array}{l}\text { The child have psychological } \\
\text { problem }\end{array}$} & Yes & 215 & 26.9 \\
\cline { 2 - 4 } & No & 585 & 73.1 \\
\hline \multirow{5}{*}{ Psychological problem } & Non & 585 & 73.1 \\
\cline { 2 - 4 } & Speech difficulty & 21 & 2.6 \\
\cline { 2 - 4 } & Aggressive & 17 & 2.1 \\
\cline { 2 - 4 } & Depression & 17 & 2.1 \\
\cline { 2 - 4 } & Escape from school & 116 & 14.5 \\
\cline { 2 - 4 } & Others & 44 & 5.5 \\
\hline \multirow{5}{*}{ The child have medical problem } & Yes & 213 & 26.6 \\
\cline { 2 - 4 } & No & 587 & 73.4 \\
\hline & Non & 587 & 73.4 \\
\cline { 2 - 4 } & Difficulty concentrating & 120 & 15.0 \\
\cline { 2 - 4 } & Disability & 5 & .6 \\
\cline { 2 - 4 } & Epileptic fit & 5 & .6 \\
\cline { 2 - 4 } & Hereditary & 43 & 5.4 \\
\cline { 2 - 4 } & Thalassemia & 36 & 5.5 \\
\cline { 2 - 4 } & Incontinence & & \\
\hline
\end{tabular}

Table 3 shows that children not have psychological and medical problem in $73.1 \%$ and 73.4 respectively. 
Table 4: The child response after hits of the study samples

\begin{tabular}{|l|c|c|}
\hline Type of Child Response & Freq. & \% \\
\hline Social withdrawal & 223 & 27.9 \\
\hline Refuse eating & 203 & 25.4 \\
\hline Hostility Towards His Family & 67 & 8.4 \\
\hline Hurt himself & 29 & 3.6 \\
\hline Escape from school & 69 & 8.6 \\
\hline Indifference & 146 & 18.3 \\
\hline Other & 63 & $\mathbf{8 0 0}$ \\
\hline Total & & $\mathbf{1 0 0 . 0}$ \\
\hline
\end{tabular}

Table 4 shows the child response after hits the children for family in the study is social withdrawal in $27.9 \%$.

Table 5: The relationship between the parent educations, Jobs with child Abuse

\begin{tabular}{|c|c|c|c|c|c|c|c|}
\hline \multirow{2}{*}{$\begin{array}{l}\text { Parent } \\
\text { Educations }\end{array}$} & \multirow{2}{*}{ Items } & \multicolumn{2}{|c|}{ Not Abused } & \multicolumn{2}{|c|}{ Abused } & \multirow{2}{*}{ Chi-seq. } & \multirow{2}{*}{ P.value } \\
\hline & & Freq. & $\%$ & Freq. & $\%$ & & \\
\hline \multirow{6}{*}{ Father Education } & Illiterate Stage & 49 & 9.5 & 26 & 9 & \multirow{6}{*}{34.95} & \multirow{6}{*}{0.000} \\
\hline & Read and write Stage & 109 & 21.3 & 74 & 25.6 & & \\
\hline & Elementary Stage & 32 & 6.2 & 37 & 13 & & \\
\hline & Intermediate Stage & 118 & 23 & 25 & 8.6 & & \\
\hline & Junior high Stage & 79 & 15.5 & 40 & 13.8 & & \\
\hline & Graduate Stage & 124 & 24.5 & 87 & 30 & & \\
\hline \multirow{6}{*}{$\begin{array}{l}\text { Mother } \\
\text { Education }\end{array}$} & Illiterate Stage & 18 & 3.5 & 30 & 10.3 & \multirow{6}{*}{62.27} & \multirow{6}{*}{0.000} \\
\hline & Read and write Stage & 107 & 21 & 83 & 28.7 & & \\
\hline & Elementary Stage & 117 & 23 & 47 & 16.3 & & \\
\hline & Intermediate Stage & 75 & 14.6 & 42 & 14.5 & & \\
\hline & Junior high Stage & 76 & 14.8 & 69 & 24 & & \\
\hline & Graduate Stage & 118 & 23 & 18 & 6.2 & & \\
\hline \multirow{4}{*}{ Father Job } & Employee & 167 & 32.6 & 131 & 45.5 & \multirow{4}{*}{13.45} & \multirow{4}{*}{0.004} \\
\hline & worker with skills & 240 & 47 & 105 & 36.2 & & \\
\hline & worker without skills & 88 & 17.2 & 43 & 14.8 & & \\
\hline & Unemployed & 16 & 3.2 & 10 & 3.5 & & \\
\hline \multirow[t]{2}{*}{ Mother Job } & Housewife & 354 & 69.2 & 192 & 66.5 & \multirow{2}{*}{0.68} & \multirow{2}{*}{0.407} \\
\hline & Employee & 157 & 30.8 & 97 & 33.5 & & \\
\hline \multicolumn{2}{|l|}{ Total } & 511 & 100.0 & 289 & 100.0 & & \\
\hline
\end{tabular}

Table 5 shows the relationship between the parent educations, job and child abuse shows high significant rate 0.000 . 
Table 6: The relationship between the social factors with child abuse

\begin{tabular}{|c|c|c|c|c|c|c|c|}
\hline \multirow{2}{*}{ Social Factors } & \multirow{2}{*}{ Items } & \multicolumn{2}{|c|}{ Not Abused } & \multicolumn{2}{|c|}{ Abused } & \multirow{2}{*}{ Chi-seq. } & \multirow{2}{*}{ P.value } \\
\hline & & Freq & $\%$ & Freq & $\%$ & & \\
\hline \multirow{4}{*}{ Family Income } & Less than 300 thousand dinars & 108 & 21.1 & 90 & 31.1 & \multirow{4}{*}{13.1} & \multirow{4}{*}{0.004} \\
\hline & $400-800$ thousand dinars & 238 & 46.5 & 108 & 37.3 & & \\
\hline & One Million & 114 & 22.4 & 55 & 19 & & \\
\hline & More than one million & 51 & 10 & 36 & 24.6 & & \\
\hline \multirow{2}{*}{$\begin{array}{l}\text { The father suffers } \\
\text { from financial loss }\end{array}$} & Yes & 161 & 31.5 & 87 & 30.1 & \multirow{2}{*}{0.170} & \multirow{2}{*}{0.680} \\
\hline & No & 350 & 68.5 & 202 & 69.9 & & \\
\hline \multirow{3}{*}{$\begin{array}{l}\text { Presence of stress at } \\
\text { work }\end{array}$} & Always & 25 & 5 & 65 & 24.5 & \multirow{3}{*}{72.84} & \multirow{3}{*}{0.00} \\
\hline & Sometime & 147 & 28.8 & 103 & 20 & & \\
\hline & Never & 339 & 66.2 & 121 & 23.5 & & \\
\hline \multirow{2}{*}{ Absence of Father } & Yes & 229 & 44.8 & 86 & 29.7 & \multirow{2}{*}{17.53} & \multirow{2}{*}{0.000} \\
\hline & No & 282 & 55.2 & 203 & 70.3 & & \\
\hline \multirow{2}{*}{ Marital Problem } & Yes & 141 & 57.5 & 64 & 22.2 & \multirow{2}{*}{2.87} & \multirow{2}{*}{0.090} \\
\hline & No & 370 & 72.5 & 225 & 77.8 & & \\
\hline \multirow{2}{*}{ Alcoholic Father } & Yes & 18 & 3.5 & 21 & 7.2 & \multirow{3}{*}{5.58} & \multirow{3}{*}{0.018} \\
\hline & No & 493 & 96.5 & 268 & 92.8 & & \\
\hline \multicolumn{2}{|l|}{ Total } & 511 & 100.0 & 289 & 100.0 & & \\
\hline
\end{tabular}

Table 6 shows that highly significant with family income, presence of stress at work, absence of father, and alcoholic father.

\section{Discussion}

The home is supposed to provide support and safety for children but can also be the place where children suffer abuse and other adverse treatment by their parents. To the best of our knowledge, this article is the first published the extent of CPA in Mosul city. In such circumstances primary and intermediate schools provide a best numerical indicator. What is taken for granted in Iraq could not be assumed neither in western countries, higher income countries and more developed countries nor in other developing countries, because of impact of wars, embargo and disasters. Thus, the findings of the present study may differ if it is compared with other findings taken in another period of time or another place. Therefore, the figure of prevalence of CPA in student $36.1 \%$. This study which could be quite helpful indicator of the problem of CPA in student in Mosul City. Review of the literature revealed a wide range of reports regarding the prevalence of CPA in children. Globally,prevalence of reported CPA varies from 2\% to $62 \%^{[14,15]}$. In US In 2006, 16\%. In 2008 It's very likely that many more children are physically abused than the number that are reported ${ }^{[12,16,17]}$. In $2015,63.4 \%$ were alleging child abuse and neglect ${ }^{[11]}$. This is correlated with the present study.

Our study shows 1:1 ratio similar gender distribution of CPA. In Sweden was stated that $50 \%$ of the girls and $28 \%$ of the boys had been exposed to $\mathrm{CPA}^{[13]}$. In US study more than one-half $54.1 \%$ of victims were female, $45.0 \%$ were men, and 0.9 percent were of unknown $\mathrm{sex}^{[14]}$. These results not correlated with the present study because of our culture that we are anxious more about female. Epidemiological studies suggest that CPA are more prevalent among children from low socioeconomic environments. $80 \%$ of this maltreatment is perpetrated by parents with poverty, in our study the association was significant in low to middle income families. Furthermore, mental health problems, low educational achievement, alcohol and drug misuse, having been maltreated oneself as a child, and family breakdown or violence between other family members are all important risk factors for parents abusing their children. These official cases are also generally skewed towards the lower end of the socioeconomic spectrum ${ }^{[2,3,5,6]}$, 
this is correlated with the current study according to the presence of stress at work, mother and father education and father job. Moreover, Researches have shown that abuse may impair the healthy development of the brain. Chronic abuse can have significant and broad consequences. Physical, mental, and emotional development may all suffer ${ }^{[12]}$. Sweden study showed that $70 \%$ of the children who reported self-injurious behaviors also reported history of some type of abuse ${ }^{[13]}$ Physical abuse, emotional abuse, and neglect were also associated with an almost 3-fold increased risk of developing eating disorders and others was associated with a 5-fold increased risk of developing bulimia Nervosa. Physical abuse was associated with a doubling of the odds of childhood behavioral and conduct disorder with a significantly increased risk of suicidal behavior compared with non-abused individuals ${ }^{[14]}$. Other study indicated that abuse in childhood increased the likelihood of adult criminal behavior by $28 \%$ and violent crime by $30 \%^{[12,14]}$.

The investigator recommend that traumatic event often trigger the development of CPA and its sequel may be eased by mediation of many factors such as: improve socioeconomic status of families to reduce stress.

\section{Conclusion}

This cross-sectional study aimed to determine the prevalence of CPA among sample of Mosul schoolchildren, using a self-reported questionnaire. A total of 800 intermediate school children,age group 14-15 years represent more than one third, similar male to female ratio,more than one third of these had CPA and abused by mothers. Quarter of them had psychological problem. The relationship between the parent educations and father's job shows high significant rate.

Recommendation: The prevalence of physical in Mosul city is high and solutions should be sought to correct the problem engaging political and social leaders, the mass media, law enforcement agencies, parents and educators through research studies done to establish what works in this field.

Funding: This research was carried out at the researcher's own expense.

Ethical Considerations: The ethical letter was written in Arabic language as it is an official language for writing letters in the college of nursing Mosul-Iraq.

\section{Conflict Interest: Nil}

\section{References}

1. Del Abuso C P, los Padres U G and suoficina D E. How to Protect Your Children From Child Abuse: A Parent's Guide. America .2005. 1-24 www. scouting.org/pubs/ypt/pdf/46-072.pdf. 2010.1-69

2. Bcheraoui C. El, Kouriye H. and Adib S.M. Physical and verbal/emotional abuse of school children, Lebanon. .EMHJ. 18(10). 1011-1020.

3. Christian C W. Child Physical Abuse: An Overview. University of Pennsylvania, USA. 2012

4. Kjellgren C, Svedin Go and Nilsson D. Child Care in Practice;Child Physical Abuse: Experiences of Combined Treatment for Children and their Parents: APilotStudy:2013.19(3)275_290http:// www.tandfonline.com/loi/cccp20.

5. Portable Guides to Investigating Child Abuse. Battered Child syndrome: investigation Physical Abuse and homicide. U S department of justice. Office of juvenile justice and delinquency prevention. Office of justice program. 2002.1-20

6. Maneta EMD and Cohen sh, Waldinger R. Links Between Childhood Physical Abuse and Intimate Partner Aggression: The Mediating Role of Anger Expression. Violence and victims. Research linking childhood physical abuse (CPA) and adult intimate. With the Compliments of Springer Publishing Company, Violence and Victim 2012. 27(3):315328.

7. Trauernicht G. The right to protection ending violence against children. 2013. 02:59.1-44

8. National commit . A Literature Review into Children Abused and/or Neglected Prior Custody 36 . Studies related to interventions to address antisocial and offending behavior. 2008

9. del Abuso C P, los Padres U G and suoficina D E. How to Protect Your Children From Child Abuse: A Parent's Guide. America .2005. 1-24 www. scouting.org/pubs/ypt/pdf/46-072.pdf

10. Day C, Hibbert P.and Cadman S. A Literature Review into Children Abused and/or Neglected Prior Custody; Youth Crime Section, Policy and Research Division, Nacro. Youth justiceboard 2008. 1-69 www.yjb.gov.uk

11. Identifying and Responding to All Forms of Abuse in Victorian Schools. PROTECT Identifying signs 
of child abuse. Education state of vectoria. Protect. Small book. 2016.1-69

12. Kolko D. Questions \& Answers About Child Physical Abuse. National child traumatic stress network NCTSN. 2011.1-5. www.NCTSN.org.

13. Annerbäck ME. Child Physical Abuse characteristics, prevalence, health and risk-taking. Department of Clinical and Experimental Medicine. Child and Adolescent Psychiatry Linköping University Sweden. 2011.1-99

14. Norman R E, Byambaa M, Rumna De, Butchart3 A, Scott J. The long-term health consequences of child physical abuse, emotional abuse, and neglect: A systematic review and meta-analysis: PLOS Medicine | 2012 9(11):1-31. www.plosmedicine. org

15. Committee on the Rights of the Child. General comment. The right of the child to freedom from all forms of violence. Convention on the Rights of the Child. 2011.(13). 1-29
16. Heisler Kand Mary EU.S. Department of Health \& Human Services Administration for Children and Families Administration on Children. Child maltreatment. Youth and Families Children's Bureau. 2015. SW Washington, kurt.heisler@acf. hhs.gov Children's Bureau

17. Perry, B. Child Abuse/Children Exposed to Family Violence Information Sheet. The destructive impact of domestic violence on children. In Alberta Children and Youth Services, Family violence it's your business: Community resource guide 2005.9-10 http://www.child.alberta.ca/home/ images/familyviolence/FVP_Communi-07643q tyResourceGuide

18. Dwyer K., Strang H and National Committee on Violence. Violence Against Children.. Printed in Australia by R. D. RUBIE, Commonwealth Government Printer, Canberra. The right to protection: Ending violence against children. 1989.3-8. 